\title{
PEMBELAJARAN KETERAMPILAN MEMBACA (MAHARAH QIRAAH) MENGGUNAKAN KORAN ELEKTRRONIK (AL-JARIDHAH AL-ELEKTRONIYAH)
}

\section{(Studi di Pondok Pesantren Darul Lughah Wal Qur'an Angsokah Timur Palengaan Daya Palengaan Pamekasan)}

\author{
Oleh: \\ Mohammad Zainal Hamdy ${ }^{1}$ \\ Email: hamdyhernandez14@gmail.com
}

\begin{abstract}
This research consists of two problems. Firstly, how is the process of learning reading skills using electronic newspapers at Darul Lughah wal Qur'an Boarding School Angsokah Timur Palengaan Daya Palengaan Pamekasan. Secondly, What is the Factors of learning reading skills using electronic newspapers at Darul Lughah wal Qur'an Boarding School Angsokah Timur Palengaan Daya Palengaan Pamekasan. This research uses qualitative research and the data source includes the teachers and students of learning reading skills using electronic newspapers at Darul Lughah wal Qur'an Boarding School Angsokah Timur Palengaan Daya Palengaan Pamekasan. And then,Data collection techniques using interviews and observationswhere the research was carried out for one month. Start from 2nd of February 2020 untill 3rd of March 2020 that the data analysis using descriptive analysis. The results of this research state that the process of learning reading skills using electronic newspapers at Darul Lughah wal Qur'an Boarding School Angsokah Timur Palengaan Daya Palengaan Pamekasanare effectiveexcept some problems like vocabulary difficulties in contemporary languages. So for all of students who studies this learning reading skills using electronic newspapers at Darul Lughah wal Qur'an Boarding School Angsokah Timur Palengaan Daya Palengaan Pamekasanis hoped to take the time to memorize difficult vocabularies, especially in contemporary languages. And for the teachers who teaches learning reading skills using electronic newspapers at Darul Lughah wal Qur'an Boarding School Angsokah Timur Palengaan Daya Palengaan Pamekasan could be more creative and innovate so that students love Arabic more than before and they are not bored in following their learning.
\end{abstract}

Key words: learning, reading skills, e-newspapers Pamekasan

${ }^{1}$ Dosen Sekolah Tinggi Ilmu Bahasa Arab (STIBA) Darul Ulum Banyuanyar

Volume 11 Nomor 1 Maret 2020

Approved: 02-01-2020, Accepted: 15-01-2020, Submitted: 09-02-2020 


\section{Pendahuluan}

Bahasa adalah alat komunikasi atau alat untuk mengungkapkan pikiran melalui bunyi yang diucapkan. ${ }^{2}$ Sebagaimana yang telah dikemukakan oleh Ibnu Jinni bahwa Bahasa adalah bunyi yang digunakan oleh suatu kelompok untuk mengungkapkan tujuan mereka. ${ }^{3}$ Bahasa Arab merupakan bahasa resmi untuk beberapa negara yang berada pada kawasan Asia Barat dan Afrika Utara. Bahasa Arab juga menjadi bahasa pendidikan, ilmu pengetahuan, diplomasi, transaksi sosial dan ekonomi, dan budaya. ${ }^{4}$

Pembelajaran bahasa Arab sudah lama dilakukan di Indonesia namun hasilnya belum optimal. Berbagai problem masih sering bermunculan dan hampir jarang terpecahkan. Problem tersebut sangat perlu mendapatkan penanganan untuk menjaga eksistensi bahasa Arab itu sendiri. Problem tersebut dapat dilihat dari beberapa factor yaitu siswa kurang siap mengikuti pelajaran bahasa dan kompleksitas nateri bahasa Arab menjadikan kesulitan tinggi pada teknik, strategi, serta metode penyampaiannya.

Aktivitas pengajaran bahasa Arab sebagai inti proses pendidikan tidak berjalan sewajarnya. Banyak guru terpaku pada buku paket (text book oriented) dan sulit menciptakan suasana pembelajaran kreatif, inovatif , dan menyenangkan. ${ }^{5}$ Faktor lain yang menjadi penghambat pembelajaran bahasa Arab antara lain kurangnya pemanfaatan sarana dan prasarana pembelajarann seperti: media pembelajaran, alat-alat permainan, dan sebagainya.

Pemanfaatan media pembelajaran adalah salah satu solusi untuk mengatasi permasalahan dalam pembelajara. Media pembelajaran

\footnotetext{
${ }^{2}$ Emil Badi' Ya'qub, Fiqh al lughah wa khasaisuha (Beirut: da rats tsaqofah al
} Islamiyyah, 1982) hlm. 22

${ }^{3}$ Mustofa Ghalayani, Jami' ad durus al Arabiyyah(Beirut: da rats tsaqofah al Islamiyyah, 1944) hlm.70

${ }^{4}$ Azhar Arsyad, Madkhol ila thuruq taklim al-lughah al-Arabiyyah (Ujung Pandang: al-ahkam, 1998), hlm.1.

${ }^{5}$ Fathul Mujib dan Nailur Rahmawati, Metode Permainan-Permainan Edukatif Dalam Bekajar Bahasa Arab (Jogjakarta: diva Press, 2013), hlm.7 
merupakan sebuah alat bantu komunikasi antara guru dan siswa untuk mempermudah penyampaian suatu informasi dalam sebuah pembelajaran. Akan tetapi yang terpenting bukan medianya saja melainkan pesan pembelajaran yang dibawakan oleh media tersebut. Penggunaan media pembelajaran secara tepat dapat membantu dalam mencapai pembelajaran yang efektif dan efisien. Disamping bentuk dari media pembelajaran yang tepat guna, dalam sebuah proses pembelajaran juga dibutuhkan keterampilan guru dalam memanfaatkan media tersebut sehingga tujuan pembelajaran dapat tercapai.

Bahasa Arab memiliki unsur bahasa meliputi: suara, kosakata dan tata bahasa, serta terintegrasi dengan keterampilan bahasa lainya meliputi: keterampilan mendengar, berbicara, membaca dan menulis. Kedua hal tersebut hendaknya diajarkan kepada para pembelajar dengan cara yang baik, tepat, dan menyenangkan agar tujuan pembelajaran yang direncakan dapat terwujud. Salah satu caranya adalah dengan adanya kreatifitas pengajar secara terus menerus, salah satunya dengan media pembelajaran yang digunakan.

Salah satu keterampilan bahasa yang sangat penting adalah membaca. Membaca adalah kunci untuk membuka khazanah pengetahuan dan kebudayaan Islam, selain itu long life education tidak akan terwujud kalau yang melakukannya tidak dapat membaca. ${ }^{6}$ Membaca juga bisa menjadi salah satu alat sampainya suatu informasi selain berkomunikasi langsung.7 Membaca juga menjadi urgen ketika seseorang menyampaikan pesan melalui sebuah tulisan.

Dari segi penyampaiannya membaca terbagi menjadi dua: ${ }^{8}$

a. Membaca nyaring (qiraah jahriyah) yaitu membaca dengan menekankan kepada aktifitas anggota bicara (lisan, bibir, dan tenggorokan untuk mengeluarkan bunyi atau suara.

\footnotetext{
${ }^{6}$ Radliyah Zaenuddin dkk, Strategi Alternative Pembelajaran Bahasa Arab (Jogjakarta: Pustaka Rihlah Group, 2005). Hlm. 71

${ }^{7}$ Abdul alim Ibrahim, Al Muwajjah Al Fanni(Kairo: dar al maarif, 1991), hlm. 87

${ }^{8}$ Zakaria Ismail, Thuruq At Tadris Al Lughah Al Arabiyyah(Dar ma'rifah jamiiyaah, 1995), hlm. 114
} 
b. Membaca dalam hati (qiraah shomitah) yaitu membaca dengan melihat huruf dan memahami makna bacaan tanpa aktifitas organ bicara.

Sedangkan menurut bentuknya membaca dibagi menjadi: ${ }^{9}$

a. Membaca intensif (qiraah mukatstsafah) yang mempunyai karakteristik: dilakukan di dalam kelas bersama pengajar, tujuannya untuk meningkatkan keterampilan utama dalam membaca dan memperkaya perbendaharaan kata serta menguasai qawaid yang dibutuhkan dalam membaca, pengajar mengawasi dan membimbing kegiatan itu serta memantau kemajuan peserta didik

b. Membaca ekstensif (qiraah muwassa'ah), jenis ini mempunyai karakteristik: kegiatan membaca dilakukan di luar kelas, tujuannya untuk meningkatkan pemahaman isi bacaan, sebelum kegiatan dilakukan pengajar mengarahkan, menentukan materi bacaan dan mendiskusikannya.

Bagi pelajar bahasa Arab yang sudah berada di tingkatan mutaqoddim, keterampilan membaca menjadi sangat penting karena mereka diwajibkan untuk menyampaikan informasi yang berasal dari sumber-sumber utama dan ditransfer pada tingakatan di bawahnya. Seperti halnya santri di Pondok Pesantren Darul Lughah wal Quran Angsokah Timur Palengaan Daya Palengaan Pamekasan diberikan kesempatan untuk mengembangkan keterampilan membacanya dengan mempelajari kosa kata bahasa Arab yang ada dalam koran-koran elektronik di website internet. Kemudian, dibedah dan dikaji untuk menambah perbendaharaan kosa kata bahasa Arab sehingga dapat meningkatkan kemampuan mereka dalam memahami teks-teks bahasa Arab yang sulit dan membutuhkan pengentahuan bahasa Arab klasik ataupun kontemporer.

Koran elektronik adalah salah satu media pembelajaran bahasa Arab yang diunduh di website-website tertentu di internet yang berisi berita dan informasi baik itu berkaitain dengan politik, ekonomi, pendidikan, dan sebagainya. Dalam pembelajaran maharah qiraah media ini menjadi materi pembelajaran dimana di dalamnya berisi kosakata baru/kontemporer yang

${ }^{9}$ Muhammad Kamil Naqoh,Ta 'lim Al Lughah Al Arabiyyah Li An Nathiqina Bi Lughatin Ukhra (Beirut: Dar audah, 1980), hlm 62 
bisa menambah perbendaharaan kata peserta didik dalam mengembangkan dan meningkatkan kemampuan membaca bahasa Arab.

Oleh karena itu penelitian ini, sekaligus memaparkan bagaimana proses kegiatan pembelajaran keterampilan membaca (maharah qiraah) menggunakan koran elektrronik (al-jaridhah al-elektroniyah) di Pondok Pesantren Darul Lughah wal Qur'an Angsokah Timur Palengaan Daya Palengaan Pamekasan agar bisa menjadi referensi bagi pecinta bahasa Arab yang ingin meningkatkan keterampilan membaca bahasa Arab terutama dalam bahasa Arab kontemporer.

Membaca adalah kegiatan yang meliputi pola berpikir, menilai, menganalisis dan memecahkan masalah. Dengan membaca setiap individu dapat mempelajari dan berinteraksi dalam dunia di luar dirinya. Kehidupan manusia tidak hanya dapat dikomunikasikan melalui media lisan semata, namun kadang memerlukan media tertulis, apalagi bila dikaitkan dengan keinginan untuk memahami khazanah intelektual Islam dan modern. Disinilah makna pentingnya membaca. ${ }^{10}$

\section{Metode Penelitian}

Metode penelitian yang digunakan dalam penelitian ini adalah metode penelitian kualitatif. Penelitian kualitatif adalah proses inkuiri yang bertujuan untuk memahami perilaku manusia dengan membangun gambaran yang utuh tentang setting budaya dan sosial tempat terjadinya perilaku tersebut. Penelitian ini melibatkan data yang berupa kata-kata yang menggambarkan pandangan orang yang diteliti. Penelitian ini dilakukan di tempat orang-orang yang diteliti sedang berinteraksi secara alami di habitat merekadan menjadi anggota komunitas yang diteliti.

Penelitian ini mencoba memahami apa, bagaimana, kapan, dan dimana peristiwa terjadi sehingga menghasilkan pemahaman tentang makna, konsep, definisi, ciri, metafora, simbol, atau deskripsi, tentang orang yang diteliti. ${ }^{11}$ Pemaknaan meliputi: perasaan, keyakinan, ide-ide,

\footnotetext{
${ }^{10}$ Radliyah Zaenuddin dkk, Strategi Alternative Pembelajaran Bahasa Arab,
} hlm. 71

${ }^{11}$ Mohammad Adnan Latief, Tanya Jawab Metode Penelitian Pembelajaran Bahasa (Malang: UNM, 2014), hlm, 67 
pemikiran ,dan kegiatan dari partisipan. Beberapa penelitian kualitatif diarahkan lebih dari sekedar memahami fenomena yang ada tetapi juga mengembangkan teori. ${ }^{12}$

Dalam rangka untuk mengumpulkan data tentang pembelajaran keterampilan membaca (maharah qiraah) menggunakan koran elektrronik (al-jaridhah al-elektroniyah) di Pondok Pesantren Darul Lughah wal Qur'an Angsokah Timur Palengaan Daya Palengaan Pamekasan, Peneliti hadir 5 kali selama satu bulan dimulai 3 Februari sampai 4 Maret 2020.

Sumber data dalam penelitian adalah: (1) guru/asatidz, (2) santri (putra/putri) yang mengikuti pembelajaran keterampilan membaca (maharah qiraah) menggunakan koran elektrronik (al-jaridhah al-elektroniyah) di Pondok Pesantren Darul Lughah wal Qur'an Angsokah Timur Palengaan Daya Palengaan Pamekasan yang berjumlah 22 orang

Dalam pengumpulan data, digunakan metode wawancara, dengan teknik wawancara terstruktur dan tidak terstruktur. Selain itu, digunakan teknik observasi, dengan Peneliti melakukan pengamatan tidak langsung dalam mengumpulkan data tentang pembelajaran keterampilan membaca (maharah qiraah) menggunakan koran elektrronik (al-jaridhah al-elektroniyah) di Pondok Pesantren Darul Lughah wal Qur'an Angsokah Timur Palengaan Daya Palengaan Pamekasan

\section{Hasil dan Pembahasan}

\section{Tujuan Pembelajaran Keterampilan Membaca (Maharah Qiraah) Menggunakan Koran Elektrronik (al-jaridhah al-elektroniyah)}

Pembelajaran keterampilan membaca (maharah qiraah) menggunakan koran elektrronik (al-jaridhah al-elektroniyah) di Pondok Pesantren Darul Lughah wal Qur'an Angsokah Timur Palengaan Daya Palengaan Pamekasan memiliki tujuan khusus yaitu agar peserta didik mampu memahami kitab kuning maupun kitab kontemporer bahasa Arab. Sebagaimana dijelaskan oleh salah satu pengajar pembelajaran ini bahwa tujuan diadakannya pembelajaran ini adalah guru berusaha memadukan

\footnotetext{
${ }^{12}$ Nana Syaodih Sukmadinata, Metode Penelitian Pendidikan(Bandung:
} RosdaKarya, 2015). Hlm.97 
kemampuan pondok-pondok salaf dengan dengan pondok modern dalam memahami teks-teks Arab baik itu yang klasik maupun kontemporer sehingga peserta didik tidak hanya mampu menguasai salah satu kitab tersebut. Melainkan dapat menguasai dua-duanya sekaligus, klasik dan kontemporer.

Karena banyak ditemui peserta didik hanya bisa menguasai salah satu teks (kitab) klasik/kontemporer. Misalnya ada peserta didik yang sangat menguasai pemahaman tentang kitab kuning namun ketika diberikan referensi berkaitan dengan kitab kontemporer menemukan kesulitan baik dalam kosakata yang baru maupun dari segi pemahaman teks secara utuh. Sebaliknya, ada peserta didik yang terbiasa dan sangat menguasai pemahaman kitab kontemporer (mu'ashiroh) namun lemah dalam memahami kitab-kitab klasik.

Adanya pembelajaran keterampilan membaca (maharah qiraah) menggunakan koran elektrronik (al-jaridhah al-elektroniyah) di Pondok Pesantren Darul Lughah wal Qur'an Angsokah Timur Palengaan Daya Palengaan Pamekasan tujuan utamanya adalah bisa memadukan dua sumber ilmu Islam tersebut sehingga peserta didik dapat bersaing mengikuti perkembangan zaman dan tidak meninggalkan sumber khazanah Islam yang sudah diwariskan oleh ulama-ulama salaf terdahulu.

\section{Langkah-langkah Pembelajaran Keterampilan Membaca (Maharah Qiraah) Menggunakan Koran Elektronik (al-jaridhah al- elektroniyah)}

Adapun hal-hal yang harus dipersiapkan oleh guru dalam pembelajaran keterampilan membaca (maharah qiraah) menggunakan koran elektrronik (al-jaridhah al-elektroniyah) di Pondok Pesantren Darul Lughah wal Qur'an Angsokah Timur Palengaan Daya Palengaan Pamekasan adalah sebagai berikut.

\section{a. Persiapan}

Sebelum proses pembelajaran guru diharuskan menyiapkan atau mengunduh materi berupa Koran yang baru terbit di website website tertentu misalnya seperti al-jazeerra untuk dijadikan media utama dalam 
pembelajaran ini. Setelah itu guru menentukan kosakata bahasa Arab baru yang ada dalam Koran yang sekiranya sulit dan tidak dipahami oleh peserta didik dan atau guru menyuruh dan menyiapkan kamus khusus kosakata klasik (contoh: kamus Munawwir) dan kosakata kontemporer (contoh: kamus al-ashri).

b. Pelaksanaan

Koran elektronik yang sudah diunduh sebelum pembelajaran ditampilkan dalam sebuah layar proyektor untuk dibaca dan dijelaskan pada peserta didik. Guru menentukan dan memberitahu kosa kata yang sulit bagi peserta didik atau menyuruh untuk mencari dalam kamus yang sudah disediakan.

Setelah itu peserta didik diperintahkan untuk menjelaskan intisari dari teks yang sudah ditentukan oleh guru. Baik itu per kalimat atau per paragraf. Kemudian guru mentashih atau memperbaiki kesalahan kesalahan dari penjelasan tersebut. Kemudian guru memerintahkan peserta didik untuk merangkum hasil dari pemahaman tentang teks tersebut kedalam poin-poin menggunakan bahasa Arab. Secara individu ataupun dengan metode muhadatsah.

\section{c. Penutup}

Di akhir jam pelajaran guru memberikan beberapa pertanyaan bahasa Arab berkaitan dengan koran yang sudah dipelajari. Mempersilahkan peserta didik untuk menjawab pertanyaan tersebut secara langsung dengan menggunakan bahasa Arab. Kadang-kadang guru memberikan sebuah pernyataan berkaitan dengan teks sedangkan peserta didik menentukan apakah pernyataan tersebut sesuai dengan teks yang dipelajari. Selain itu guru juga memberikan tugas untuk membuat pertanyaan yang jawabannya ada di dalam teks pembahasan.

\section{Strategi Pembelajaran Keterampilan Membaca (Maharah Qiraah) Menggunakan Koran Elektronik (al-Jaridhah al-Elektroniyah)}

Sebelum masuk lebih jauh pada metode dan strategi, diharuskan mengetahui beberapa pendekatan dalam pembelajaran bahasa Arab. Pertama, pendekatan manusiawi (al-amdkhal al insani) yaitu pendekatan 
yang sangat fokus perhatiannya pada peserta didik. Kedua, pendekatan berbasis media (al madkhal at taqni), yaitu pendekatan yang mengandalkan pada teknik penguasaan penggunaan media pembelajaran. Ketiga, pendekatan aural-oral (al madkhal as sam'i as syafahi) pendekatan ini berasumsi bahwa bahasa adalah apa yang didengar dan diucapkan. Keempat, pendekatan analisis dan non-analisis (al madkhal at tahlili wa ghairu tahlili) yaitu pendekatan formal. Terakhir adalah pendekatan komunikatif (al madkhal al ittishali) adalah pendekatan yang memfokuskan pada kemampuan komunikasi aktif dan praktis. ${ }^{13}$ Pendekatan ini menentukan pada arah pemilihan strategi dan metode yang tepat agar sesuai dengan tujuan yang ingin dicapai.

Tidak ada strategi apapun yang dianggap paling ideal untuk diterapkan dalam sebuah proses pembelajaran bahasa Arab, karena masing masing memiliki kelemahan dan kelebihan ${ }^{14}$ yang dapat saling melengkapi antara satu dengan yang lainnnya.

Adapun strategi yang digunakan dalam pembelajaran keterampilan membaca (maharah qiraah) menggunakan koran elektrronik (al-jaridhah alelektroniyah) di Pondok Pesantren Darul Lughah wal Qur'an Angsokah Timur Palengaan Daya Palengaan Pamekasan adalah sebagai berikut:

a. Qiraah Muwajjahah, dalam strategi ini peserta didik diperintahkan untuk menjawab pertanyaan-pertanyaan yang sudah ditentukan oleh guru dan peserta didik membahas pertanyaan tersebut serta memberikan ulasannya.

b. Mudzakarat al-Talamidz, dalam strategi ini peserta didik diperintahkan untuk menentukan/menggarisbawahi kosa kata yang sulit atau tidak dipahami kemudian guru tidak langsung menjawab arti kosa kata tersebut akan tetapi tanyakan lagi (sharing) pada teman yang lain untuk menjawab arti kosa kata tersebut.

c. Qiraah Jahriyah, dalam strategi ini peserta didik dibagi menjadi beberapa kelompok dan masing-masing kelompok diberikan tugas satu paragraf

hlm. 36

\footnotetext{
${ }^{13}$ Radliyah Zaenuddin dkk, Strategi Alternative Pembelajaran Bahasa Arab,
}

${ }^{14}$ Zulhannan, Teknik Pembelajaran Bahasa Arab Interaktif (Jakarta: Raja Grafindo, 2015), hlm. 31 
teks untuk dipahami dan dicari arti kosa katanya, setelah itu perwakilan masing-masing kelompok diperintahkan unruk membaca nyaring di depan kelas secara bergantian sehingga pada akhirnya dapat memahami teks secara keseluruhan.

d. Talkhis Jama'i, setelah peserta didik memahami keseluruhan teks bacaan guru memerintahkan mereka untuk membuat resume atau poin-poin inti dari masing masing paragraf unruk kemudian dijelaskan dan disampaikan di depan kelas menggunakan bahasa Arab.

e. Akhziyat al-Nash, strategi ini digunakan untuk memahami teks yang memiliki beberapa segmen. Peserta didik dibagi menjadi beberapa kelompok sesuai jumlah segmen yang ada dalam teks. Minta setiap kelompok untuk memahami tugas masing-masing segmen yang diberikan. Kemudian guru meminta perwakilan dari setiap kelompok untuk menyampaikan hasil pemahaman kelompok masing masing di kelompok lain secara bergantian dan berurutan.

f. As'ilah wa ajwibah, dalam strategi ini dituntut adanya interaksi antara guru dan peserta didik atau peserta didik dengan peserta didik

g. Muhadatsah, dalam strategi ini peserta didik diminta untuk bermuhadatsah dengan menggunakan bahasa Arab tentang teks yang sudah dipelajari dan dipahami. Hal ini melatih peserta didik untuk berpikir logis tentang teks pelajaran dan sekaligus melatih keterampilan berbicara.

4. Media Pembelajaran Keterampilan Membaca (Maharah Qiraah) Menggunakan Koran Elektrronik (al-Jaridhah al-Elektroniyah)

Dalam proses pembelajaran media pembelajaran memiliki tiga peranan penting, yaitu:

a. Peranan sebagai penarik perhatian (attentional role)

Dalam peranannya sebagai penarik perhatian siswa, media bersifat mengundang perhatian peserta didik, meningkatkan rasa keingintahuan, serta menyampaikan informasi.

b. Peran komunikasi (communication role) 
Dalam peranannya sebagai pelancar komunikasi, media berperan dalam mendorong dan membantu siswa untuk memahami pesan tertentu yang ingin disampaikan oleh guru.

c. Peran retensi (retention role)

Dalam peran retensi, media membantu pembelajar untuk mengingat konsep-konsep penting yang diperoleh selama pelajaran. ${ }^{15}$

Sedangkan klasifikasi media terdiri dari:

a. Wasail al-sam'iyah, seperti: tape radio atau laboratorium bahasa.

b. Wasail al bashariyah, dibagi menjadi media yang diproyeksikan seperti: slide dan proyektor, dan media yang tidak diproyeksikan seperti: papan tulis, gambar diam, peta dan lain sebagainya.

c. Wasail al-sam'iyah al bashariyah, misalnya seperti: film, video youtube, televise, dan sebagainya.

d. Multimedia, misalnya seperti: computer pembelajaran bahasa Arab dan internet.

e. Bithaqat, seperti bithaqat al-asilah wa al-ajwibah ${ }^{16}$

Berikut beberapa media yang digunakan dalam Pembelajaran keterampilan membaca (maharah qirah) menggunakan koran elektrronik (al-jaridhah al-elektroniyah) di Pondok Pesantren Darul Lughah wal Qur'an Angsokah Timur Palengaan Daya Palengaan Pamekasan:

a. Slide dan proyektor, media ini digunakan guru ketika menampilkan koran elektronik pada peserta didik sehingga peserta didik tidak diharuskan untuk menulis teks koran tersebut.

b. Papan tulis, media ini digunakan guru ketika ingin menjelaskan kosa kata yang sulit atau asal dari kosa kata tersebut dan juga media ini digunakan ketika guru ingin menjelaskan hal-hal berkaitan dengan materi.

${ }^{15}$ Abdul Wahab Rosyidi, Media Pembelajaran Bahasa Arab (Malang: UIN Malang Press, 2009), hlm. 20

${ }^{16}$ Maimun Nawawi, Media Pembelajaran Bahasa Arab Teori Dan

Praktek(Pamekasan: STAIN Pamekasan Press, 2009), hlm.81

Volume 11 Nomor 1 Maret 2020

Approved: 02-01-2020, Accepted: 15-01-2020, Submitted: 09-02-2020 
c. Kamus/mu'jam, media ini digunakan sebagai alat bantu mencari kosa kata sulit yang tidak dipahami baik oleh guru dan peserta didik.

d. Komputer dan jaringan internet atau wifi, media ini sangat diperlukan ketika guru membutuhkan materi tambahan tentang koran elektronik dan atau ketika ingin mengunduh koran elektronik itu sendiri.

d. Faktor-Faktor yang Mempengaruhi Pembelajaran Keterampilan Membaca (Maharah Qiraah) Menggunakan Koran Elektronik (alJaridhah al-Elektroniyah)

Adapun faktor-faktor yang mempengaruhi pembelajaran keterampilan membaca (maharah qiraah) menggunakan koran elektrronik (al-jaridhah al-elektroniyah) di Pondok Pesantren Darul Lughah wal Qur'an Angsokah Timur Palengaan Daya Palengaan Pamekasan di antaranya: peserta didik, guru serta materi dan media.

Peserta didik di Pondok Pesantren Darul Lughah wal Qur'an Angsokah Timur Palengaan Daya Palengaan Pamekasan terdiri dari berbagai kalangan usia, tempat, begitu pun tujuan. Ada yang memang benar benar ingin belajar bahasa Arab dan ada pula yang hanya belajar berdasar pemaksaaan dari orang tua, artinya tidak memiliki motivasi dalam belajar bahasa Arab. Hal ini menyebabkan kecenderungan peserta didik lalai dan malas dalam proses kegiatan pembelajaran yang menyebabkan sulitnya tujuan pembelajaran tercapai secara maksimal.

Walaupun demikian adapula peserta didik yang memiliki tekad dan kemampuan dalam mengembangkan kemampuan bahasa Arabnya sehingga ini menjadi hal ini bisa menjadi motivasi bagi peserta didik yang terkesan malas dalam kegiatan pembelajaran.

Kedua, guru juga menjadi faktor penting dalam kesuksesan pembelajaran keterampilan membaca (maharah qiraah) menggunakan koran elektrronik ini. Dengan kemampuan dan keprofesionalan guru inilah yang dapat membangkitkan motivasi dan minat belajar peserta didik dalam pembelajaran keterampilan membaca (maharah qiraah) menggunakan koran elektrronik (al-jaridhah al-elektroniyah) di Pondok Pesantren Darul Lughah wal Qur'an Angsokah Timur Palengaan Daya Palengaan Pamekasan ini, 
baik itu bagi peserta didik yang mampu apalagi yang tidak punya tujuan dan arah belajar.

Kemudian ketersediaan media menjadi hal yang kalah penting dalam proses pembelajaran agar keterampilan membaca efektif tercapai. Tanpa adanya media berdampak pada ketersediaan materi pembelajaran yang nantinya akan menyebabkan proses pembelajaran tidak bisa dilaksanakan atau terhambat karena butuh waktu yang tidak sebentar dalam proses penyiapan materi pembelajaran.

\section{Penutup}

Proses pembelajaran keterampilan membaca (maharah qiraah) menggunakan koran elektrronik (al-jaridhah al-elektroniyah) di Pondok Pesantren Darul Lughah wal Qur'an Angsokah Timur Palengaan Daya Palengaan Pamekasan berjalan dengan efektif dengan langkah-langkah terdiri dari persiapan, pelaksanaan, dan penutup yang diisi dengan evaluasi pembelajaran itu sendiri.

Adapun strategi yang digunakan dalam pembelajaran keterampilan membaca (maharah qiraah) menggunakan koran elektrronik (al-jaridhah alelektroniyah) di Pondok Pesantren Darul Lughah wal Qur'an Angsokah Timur Palengaan Daya Palengaan Pamekasan di antaranya: qiraah muwajjahah, qiraah Jahriyah, mudzakarat talamidz, talkhis jama'i dan sebagainya.Strategi ini terbukti efektif sehingga peserta didik tidak merasa bosan dalam kegiatan pembelajaran keterampilan membaca (maharah qiraah) menggunakan koran elektrronik (al-jaridhah al-elektroniyah) di Pondok Pesantren Darul Lughah wal Qur'an Angsokah Timur Palengaan Daya Palengaan Pamekasan berlangsung.

Sedangkan untuk menunjang strategi yang digunakan media edukatif, menarik dan modern seperti: penggunaan internet dan wifi ketika mendownload materi begitupun penggunaan LCD proyektor sehingga memudahkan guru dalam menyampaikan materi maupun peserta didik saat menerima materi pembelajaran.

Faktor-faktor yang mendukung pembelajaran keterampilan membaca (maharah qiraah) menggunakan koran elektrronik (al-jaridhah alelektroniyah) berasal dari peserta didik itu sendiri dan guru serta media dan 
materi yang diajarkan. Walaupun ada juga faktor yang mengganggu kegiatan pembelajaran keterampilan membaca (maharah qiraah) menggunakan koran elektrronik (al-jaridhah al-elektroniyah) di Pondok Pesantren Darul Lughah wal Qur'an Angsokah Timur Palengaan Daya Palengaan Pamekasan ini, akan tetapi hal itu tidak begitu mempengaruhi ketercapaian tujuan pembelajaran yang berjalan dengan afektif dan efisien.

\section{DAFTAR PUSTAKA}

Arsyad, Azhar. 1998. Madkhol Ila Thuruq Taklim al-Lughah al-Arabiyyah. Ujung Pandang: Al-Ahkam.

Ibrahim, Abdul Alim. 1991. Al Muwajjah Al Fanni. Kairo: Dar al Maarif.

Ismail, Zakaria. 1995. Thuruq At Tadris Al Lughah Al Arabiyyah. Dar Ma'rifah Jamiiyaah.

Ghalayani, Mustofa. 1994. Jami' ad Durus al Arabiyyah (Beirut: Da Rats Tsaqofah Al Islamiyyah.

Mujib, Fathul dan Rahmawati, Nailur. 2013. Metode Permainan-Permainan Edukatif Dalam Bekajar Bahasa Arab. Jogjakarta: Diva Press.

Latief, Mohammad Adnan. 2014. Tanya Jawab Metode Penelitian Pembelajaran Bahasa. Malang: UNM.

Naqoh, Muhammad Kamil. 1980. Ta'lim Al Lughah Al Arabiyyah Li An Nathiqina Bi Lughatin Ukhra. Beirut: Dar Audah.

Nawawi, Maimun. 2009. Media Pembelajaran Bahasa Arab Teori dan Praktek. Pamekasan: STAIN Pamekasan Press.

Rosyidi, Abdul Wahab. 2009. Media Pembelajaran Bahasa Arab. Malang: UIN Malang Press.

Sukmadinata, Nana Syaodih. 2015. Metode Penelitian Pendidikan. Bandung: Rosda Karya. 
Ya'qub, Emil Badi'. 1982. Figh al Lughah wa Khasaisuha. Beirut: Da Rats Tsaqofah al Islamiyyah.

Zaenuddin, Radliyah, dkk. 2005. Strategi Alternative Pembelajaran Bahasa Arab. Jogjakarta: Pustaka Rihlah Group.

Zulhannan. 2015. Teknik Pembelajaran Bahasa Arab Interaktif. Jakarta: Raja Grafindo. 